\title{
Identifikasi Struktur Bawah Permukaan Berdasarkan Metode Magnetotellurik di Kawasan Panas Bumi Wapsalit Kabupaten Buru Provinsi Maluku

\author{
Siti Masyitah Fitrida ${ }^{1 *}$, Joko Sampurno1), Okto Ivansyah²) , Muhammad Kholid ${ }^{3)}$
}

\author{
1)Program Studi Fisika, Jurusan Fisika, Fakultas MIPA, Universitas Tanjungpura \\ 2) Program Studi Teknologi Pengolahan Hasil Perkebunan, Politeknik Negeri Pontianak \\ 3)Kelompok Bawah Permukaan, Pusat Sumber Daya Geologi Bandung \\ *Email: sitimasyitahfitrida@ymail.com
}

\begin{abstract}
Abstrak
Metode magnetotellurik (MT) telah diaplikasikan untuk mengidentifikasi struktur bawah permukaan kawasan Panas Bumi Wapsalit. Kawasan ini terletak di Kabupaten Buru Provinsi Maluku. Pengolahan data dilakukan dengan tahapan: mengubah data mentah dalam domain waktu ke domain frekuensi, pembuatan grafik resistivitas semu terhadap frekuensi dan grafik fase terhadap frekuensi, smoothing grafik dan pemodelan inversi dengan hasil akhir berupa distribusi sebaran resistivitas 2D. Penelitian bertujuan untuk menganalisis struktur bawah permukaan berdasarkan distribusi nilai resistivitas. Hasil pengolahan data menunjukkan tiga lapisan dengan rentang nilai resistivitas 1-32 $\Omega \mathrm{m}, 32-139 \Omega \mathrm{m}$ dan lebih dari $139 \Omega \mathrm{m}$, masing-masing diinterpretasi sebagai batu penudung (caprock), reservoir dan batuan dasar (basement).
\end{abstract}

Kata kunci : magnetotellurik (MT), resistivitas, panas bumi, Wapsalit

\section{Latar Belakang}

Seiring berjalannya waktu, peningkatan industri dan jumlah penduduk menyebabkan konsumsi energi terus meningkat setiap tahunnya tidak terkecuali energi listrik. Hingga saat ini sebagian besar energi listrik di Indonesia masih tergantung dengan bahan bakar fosil. Menurut CRS (Congressional Research Services) cadangan minyak bumi dunia hanya cukup untuk 30 sampai dengan 50 tahun kedepan terhitung sejak tahun 2002 (Prihandana dan Hendroko, 2008). Menghadapi krisis energi yang akan terjadi maka diperlukan berbagai solusi berupa energi terbarukan yang dapat dimanfaatkan untuk mengatasi ketergantungan terhadap bahan bakar fosil. Salah satu energi terbarukan yang berpotensi untuk dikembangkan adalah energi panas bumi.

Energi panas bumi adalah energi yang tersimpan dalam bentuk air atau uap panas pada kondisi geologi tertentu pada kedalaman beberapa kilometer di dalam kerak bumi (Santoso, 2012). Energi panas bumi merupakan energi yang bersih, terbarukan dan merupakan energi berkelanjutan yang tidak menambah emisi dunia (Daud, 2010). Energi panas bumi diperoleh dari sistem panas bumi yang memiliki karakteristik komponen yang khas diantaranya terdapat lapisan dengan patahan yang terhubung dengan lapisan yang berisi fluida panas, jalan masuk air dingin mengalir untuk mengisi ulang sistem dan tempat masuknya fluida magma dan adanya sumber panas (Grant dan Bixley, 2011). Saat ini energi panas bumi telah dimanfaatkan sebagai pembangkit listrik di 24 negara di dunia termasuk Indonesia (Bandono, 2011).
Secara geologis, Indonesia terletak pada pertemuan tiga lempeng tektonik utama yaitu Lempeng Eurasia, Indo-Australia dan Pasifik (Saptadji, 2001). Pergerakan ketiga lempeng tersebut akan menghasilkan tumbukan yang mana merupakan faktor terbentuknya sumber energi panas bumi di Indonesia dengan manifestasi permukaan berupa gunung api. Keadaan geologis yang dilalui oleh banyak gunung api membuat potensi energi panas bumi di Indonesia cukup besar, mencakup 40 persen potensi panas bumi dunia. Potensi tersebut tersebar di 251 lokasi pada 26 provinsi dengan total potensi energi 27.140 Megawatt atau setara dengan 219 Milyar Barrel minyak (Pertamina, 2014). Menurut Ketua Asosiasi Panas Bumi Indonesia (API) Abadi Purnomo, potensi energi panas bumi Indonesia yang mencapai 40 persen merupakan yang terbesar di dunia. Akan tetapi dari segi pengembangan energi panas bumi, Indonesia masih berada di urutan ketiga setelah Amerika Serikat dan Filipina (Christina, 2013).

Mengingat energi panas bumi di Indonesia yang berpotensi cukup besar maka diperlukan adanya eksplorasi untuk memaksimalkan pengembangan dan pemanfaatan. Salah satu dari sekian banyak potensi energi panas bumi di Indonesia adalah daerah panas bumi Wapsalit, Kabupaten Buru, Provinsi Maluku. Pada daerah panas bumi Wapsalit, telah dilakukan survei geofisika terpadu yaitu menggunakan metode geolistrik, gravitasi dan magnetik. Survei geofisika terpadu tersebut bertujuan mengetahui indikasi batuan perangkap panas, suhu fluida di kedalaman, struktur permukaan 
dan bawah permukaan (PSDG, 2012). Untuk menegaskan potensi panas bumi di daerah tersebut maka dilakukan survei geofisika dengan metode magnetotellurik (MT). Metode MT diaplikasikan untuk memastikan berbagai komponen penting dalam sistem panas bumi seperti batuan penudung, reservoir dan sumber panas. Struktur bawah permukaan dapat dianalisis dan diidentifikasi sebagai komponen panas bumi mengacu pada hasil akhir berupa penampang sebaran resistivitas bawah permukaan. Oleh karena itu pada penelitian ini diaplikasikan metode magnetotellurik di daerah panas bumi Wapsalit untuk mengetahui struktur bawah permukaannya. Hasil akhir pengolahan data adalah berupa model sebaran resistivitas bawah permukaan 2D.

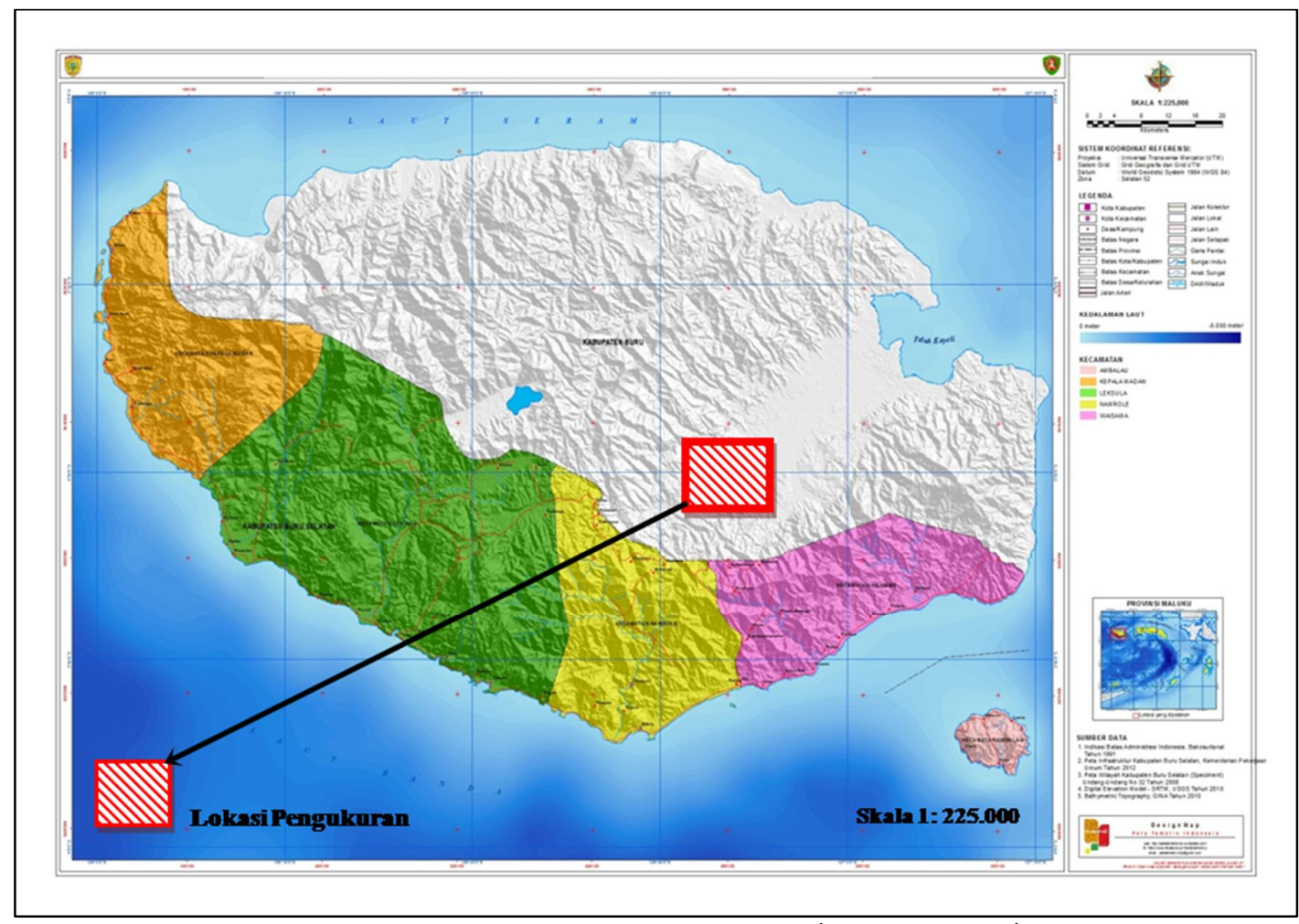

Gambar 1. Lokasi Survei Magnetotellurik (Tim Peta, 2014)

\section{Metodologi \\ Metode Magnetotellurik (MT)}

Metode magnetotellurik (MT) merupakan metode elektromagnetik pasif yang melibatkan pengukuran fluktuasi medan listrik dan medan magnet alami yang saling tegak lurus di permukaan bumi yang dapat digunakan untuk mengetahui nilai konduktivitas batuan di bawah permukaan bumi dari kedalaman beberapa meter hingga ratusan kilometer. Metode MT menggunakan frekuensi dengan kisaran $10^{-5} \mathrm{~Hz}$ $10^{3} \mathrm{~Hz}$ (Simpson dan Bahr, 2005).

Sifat-sifat perambatan gelombang EM didasarkan pada persamaan Maxwell sebagai berikut:

$$
\begin{aligned}
& \nabla x \vec{E}=-\frac{\partial \vec{B}}{\partial t} \\
& \nabla x \vec{H}=\vec{J}+\frac{\partial \vec{D}}{\partial t}
\end{aligned}
$$

$$
\begin{aligned}
& \nabla \bullet \vec{D}=q \\
& \nabla \bullet \vec{B}=0
\end{aligned}
$$

dengan $\vec{D}(\mathrm{~V} / \mathrm{m})$ adalah medan listrik $\vec{H}(\mathrm{~A} / \mathrm{m})$ adalah medan magnetik, B (Weber/ $\mathrm{m}^{2}$ atau T) adalah fluks atau induksi magnetik, $\vec{D}\left(\mathrm{C} / \mathrm{m}^{2}\right)$ adalah perpindahan muatan listrik dan $q$ $\left(\mathrm{C} / \mathrm{m}^{3}\right)$ adalah rapat muatan listrik. $\vec{J}$ adalah rapat arus dan $\partial \vec{D} / \partial t \quad\left(\mathrm{~A} / \mathrm{m}^{2}\right)$ adalah perpindahan arus terhadap waktu.

Medan elektromagnetik (EM) akan teratenuasi ketika melewati lapisan konduktif. Untuk dapat memperkirakan kedalaman penetrasi atau kedalaman investigasi gelombang EM dapat digunakan besaran skin depth. Skin depth didefinisikan sebagai kedalaman pada suatu medium homogen dimana amplitudo gelombang EM telah tereduksi menjadi 1/e dari amplitudonya di permukaan bumi (Grandis, 2013). Nilai skin depth dipengaruhi oleh resistivitas bahan dan frekuensi yang digunakan 
(Perdana, 2011). Besaran tersebut dirumuskan sebagai berikut.

$$
\delta=\sqrt{\frac{2 \rho}{\omega \mu_{o}}}
$$

Dengan $\rho$ adalah tahanan jenis medium homogen, $\mu_{0}$ adalah permeabilitas magnetik pada ruang hampa udara $\left(4 \pi \times 10^{-7}\right)$ dan $\omega$ adalah frekuensi sudut. Persamaan (5) dapat ditulis seperti persamaan dibawah ini.

$$
\delta \approx 503 \sqrt{\frac{\rho}{f}}
$$

Nilai tersebut diperoleh setelah mensubstitusi semua nilai konstanta yang telah ditetapkan dan mensubstitusi ekivalensi nilai $\omega=2 \pi f$ sehingga muncul $f$ yang merupakan frekuensi.

Data

Data yang digunakan pada penelitian merupakan data sekunder berupa datahasil survei magnetotellurik dalam domain waktu yang diperoleh di Pusat Sumber Daya Geologi (PSDG) Bandung. Lokasi survei magnetotellurik berada di Kawasan Panas Bumi Wapsalit, Kabupaten Buru, Maluku. Daerah ini berada pada koordinat $126^{\circ} 47^{\prime} 40^{\prime \prime}-126^{\circ} 56^{\prime} 47^{\prime \prime}$ BT dan $3^{\circ} 34^{\prime} 16^{\prime \prime}-3^{\circ} 26^{\prime} 09^{\prime \prime} \mathrm{LS}$ atau pada koordinat antara 9608000 - $9620000 \mathrm{mU}$ dan 257000 $271000 \mathrm{mT}$ pada sistem koordinat UTM, zona 52 belahan bumi selatan.

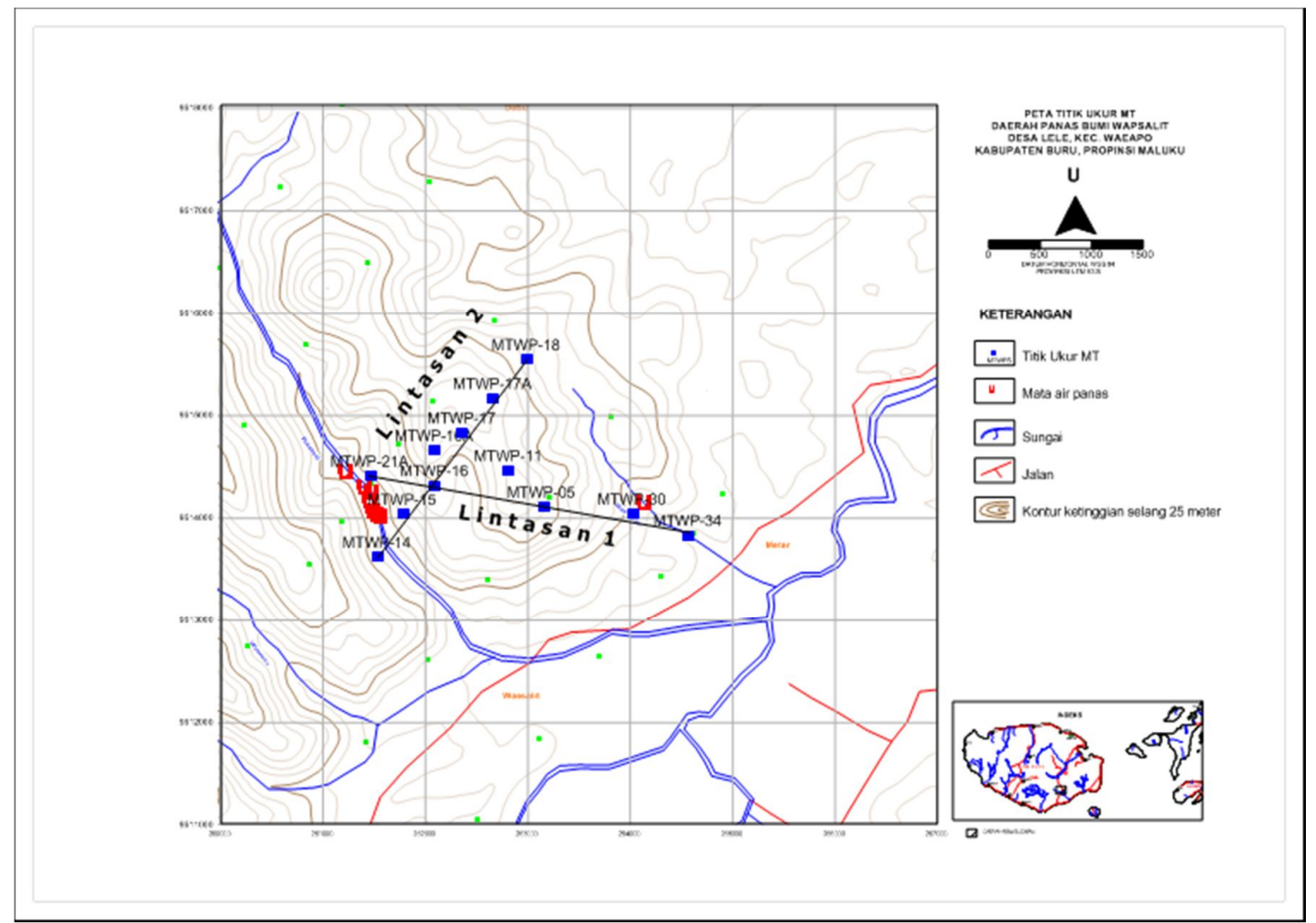

Gambar 2. Peta Titik Ukur (PSDG, 2012)

\section{Pengolahan Data}

Pengolahan data magnetotellurik pada penelitian ini menggunakan tiga perangkat lunak yaitu SSMT 2000, MT EDITOR dan WinGLink. Proses dimulai dengan mengubah data mentah yang berasal dari MT unit yang memiliki format domain waktu ke domain frekuensi menggunakan perangkat lunak SSMT 2000. Setelah itu data dengan domain frekuensi diplot menjadi kurva resistivitas semu dan fase terhadap frekuensi yang dilakukan pada perangkat lunak MT EDITOR. Pada tahap ini grafik juga akan diperhalus untuk menghasilkan sebuah kurva tahanan jenis semudengan menonaktifkan setiap cuplikan data crosspowers
(XPR) yang dipengaruhi oleh gangguan. Terakhir yang dilakukan adalah proses inversi 2Duntuk mendapatkan penampang bawah permukaandi lintasan pengukuran menggunakan perangkat lunak WinGLink.

Secara umum, permasalahan inversi dapat dituliskan dalam bentuk persamaan :

$$
\mathbf{d}=\mathbf{F}(\mathbf{m})+\mathbf{e}
$$

dengan $\mathbf{d}$ adalah vektor data, $\mathbf{m}$ adalah vektor model, e adalah vektor error dan $\mathbf{F}$ adalah fungsi forward modelling. Pemodelan inversi pada perangkat lunak WinGlink menggunakan metode inversi Nonlinear Conjugate Gradien 
(NLCG). Metode NLCG digunakan untuk meminimalisasi fungsi objektif yang didefinisikan sebagai berikut (Rodi dan Mackie, 2001):

$\Psi(m)=(\mathbf{d}-\mathbf{F}(\mathbf{m}))^{T} V^{-1}(\mathbf{d}-\mathbf{F}(\mathbf{m}))+\lambda \mathrm{m}^{T} L^{T} L m$

dengan $\lambda$ adalah parameter regulasi yang merupakan bilangan positif. $\mathrm{V}$ adalah matriks yang mengatur variasi vektor error e dan $\mathrm{L}$ adalah matriks operator. Algoritma NLCG menggunakan variasi Polak-Ribiere NLCG untuk meminimalisasi persamaan fungsi objektif. Rangkaian model untuk NLCG ditentukan oleh penentuan variabel minimalisasi fungsi objektif dimana diberikan model awal $\mathrm{m}_{0}$, sehingga persamaan model berubah menjadi (Rodi dan Mackie, 2001):

$m_{\ell+1}=m_{\ell}+\alpha_{\ell} p_{\ell}$

dengan $m_{\ell+1}$ merupakan model baru berupa hasil dari model awal yang telah ditambah dengan sistem yang dapat mempercepat proses inversi atau disebut juga preconditioner (Amriyah, 2012). Penerapan metode NLCG untuk meminimumkan fungsi objektif pada persamaan (12) memberikan solusi:

$$
\begin{aligned}
m_{\ell+1}= & m_{\ell}-\left[J_{\ell}^{T} J_{\ell}+H_{\ell}^{T}(\mathbf{F}(\mathbf{m})-\mathbf{d})+\lambda^{1 / 2}\right. \\
& \left.L^{T} L\right]^{-1} \times\left[J_{\ell}^{T}(\mathbf{F}(\mathbf{m})-\mathbf{d})\right]
\end{aligned}
$$

Pada model 2D magnetotellurik, resistivitas bervariasi dalam arah horisontal sesuai lintasan (sumbu $\mathrm{x}$ ) dan dalam arah vertikal atau kedalaman (sumbu z) sehingga $\rho(y, z)$. Medium didiskretisasi menjadi blok-blok dengan geometri tetap sehingga parameter model adalah resistivitas tiap blok. Ukuran blok dibuat tidak seragam untuk menggambarkan resolusi data MT yang berkurang terhadap jarak dan kedalaman serta untuk penerapan syarat batas pada penyelesaian persamaan diferensial menggunakan metode beda hingga atau finite difference. Dekomposisi persamaan yang dihasilkan dengan memperlihatkan geometri model 2D menghasilkan persamaan medan EM yang diidentifikasi sebagai polarisasi transverse electric (TE) dan transverse magnetic (TM). Pada polarisasi $\mathrm{TE}$ medan listrik $\mathrm{E}_{\mathrm{x}}$ dan medan magnet $\mathrm{H}_{\mathrm{y}}$ masing-masing sejajar dan tegak lurus dengan arah struktur. Persamaan yang berlaku adalah (Grandis, 2009):

$$
\begin{aligned}
& \frac{\partial^{2} E x}{\partial y^{2}}+\frac{\partial^{2} E x}{\partial z^{2}}=i \omega \mu_{0} \sigma E x \\
& H y=-\frac{1}{i \omega \mu_{0}} \frac{\partial E x}{\partial z}
\end{aligned}
$$

Pada polarisasi (TM) medan magnet $\mathrm{H}_{\mathrm{x}}$ dan medan listrik $\mathrm{E}_{\mathrm{y}}$ masing-masing sejajar dan tegak lurus dengan arah struktur. Persamaan yang berlaku adalah (Grandis, 2009):

$$
\begin{aligned}
& \frac{\partial}{\partial y}\left(\rho \frac{\partial H x}{\partial y}\right)+\frac{\partial}{\partial z}\left(\rho \frac{\partial H x}{\partial z}\right)=i \omega \mu_{0} \sigma H x \\
& E y=\rho \frac{\partial H x}{\partial z}
\end{aligned}
$$

Untuk pemodelan kedepan pada polarisasi TE, terlebih dahulu dihitung medan listrik Ex pada grid menggunakan persamaan berikut :

$$
\begin{aligned}
& \frac{E x_{(y+1, z)}-2 E x_{(y, z)}+E x_{(y-1, z)}}{\Delta y^{2}}+ \\
& \frac{E x_{(y, z+1)}-2 E x_{(y, z)}+E x_{(y, z-1)}}{\Delta z^{2}}= \\
& i \omega \mu_{0} \sigma E x_{(y, z)}
\end{aligned}
$$

yang merupakan hampiran beda hingga dari pers (11) dan hasilnya kemudian digunakan untuk menghitung Hy melalui penyelesaian persamaan diferensial secara numerik seperti diperlihatkan pada persamaan berikut :

$$
H y=-\frac{1}{i \omega \mu_{0}} \frac{E x_{(y, \mathrm{z}+1)}-E x_{(y, z-1)}}{2 \Delta z}
$$

Hal yang sama juga dilakukan untuk polarisasi TM menggunakan persamaan (13) dan (14) dengan pendekatan beda hingga. Secara umum fungsi yang menghubungkan data dengan parameter model adalah fungsi non linier. 


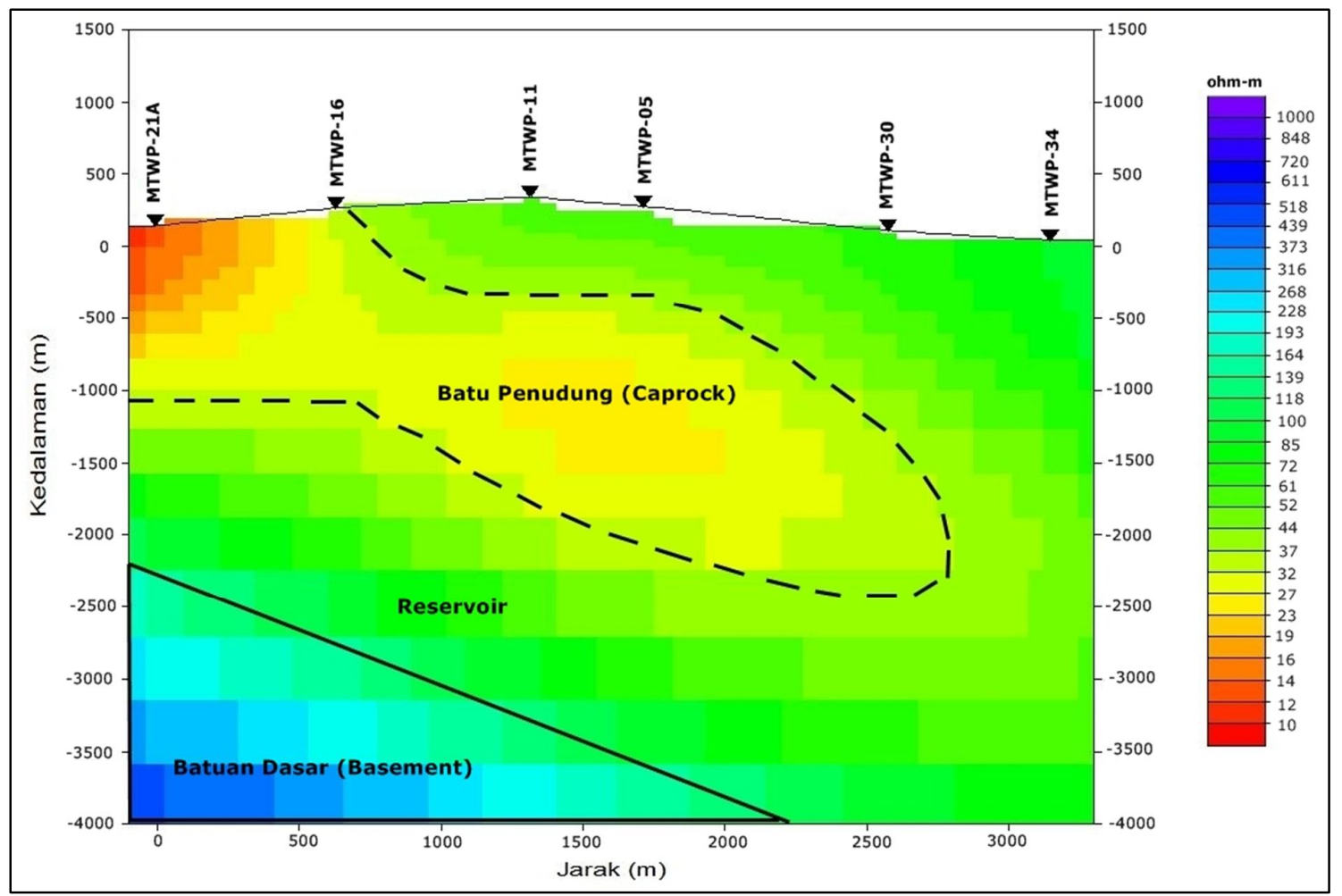

Gambar 3. Model Resistivitas Semu 2D Lintasan 1

\section{Hasil dan Pembahasan Interpretasi model sebaran resistivitas semu 2D lintasan 1}

Lintasan 1 terdiri dari titik pengukuran MTWP-21A, MTWP 16, MTWP 11, MTWP 05, MTWP-30 dan MTWP 34, berarah dari barat laut hingga tenggara. Pada hasil inversi 2D pada gambar 3, secara umum terlihat adanya tiga sebaran resistivitas utama. Terdapat pola sebaran resistivitas rendah dengan rentang nilai antara 1-32 $\Omega \mathrm{m}$ ditunjukkan dengan warna merah hingga kuning, sebaran pola resistivitas sedang dengan rentang nilai 32-139 $\Omega \mathrm{m}$ ditunjukkan dengan warna hijau dan sebaran resistivitas tinggi dengan nilai resistivitas $>139 \Omega$ m ditunjukkan dengan warna biru muda hingga biru tua.

Sebaran resistivitas rendah menyebar di bawah permukaan titik MTWP-21A dan mengarah diagonal menuju tenggara mencapai kedalaman $2500 \mathrm{~m}$ di bawah permukaan titik MTWP-30. Sebaran resistivitas rendah diduga merupakan lapisan batu penudung. Batu penudung (caprock) merupakan batuan ubahan yang terjadi akibat adanya interaksi antara fluida panas dengan batuan yang ditunjukkan dengan respon tahanan jenis yang rendah. Lapisan batu penudung merupakan lapisan impermeabel yang berfungsi untuk menjaga panas agar tetap terakumulasi di dalam zona reservoir (Kadir, 2011).

Di bawah sebaran resistivitas rendah terdapat sebaran resistivitas sedang. Sebaran resistivitas sedang mulai muncul di kedalaman $1200 \mathrm{~m}$ di bawah titik pengukuran MTWP-21A menyebar secara diagonal hingga mencapai kedalaman $4000 \mathrm{~m}$ di bawah titik pengukuran MTWP-34. Sebaran resistivitas sedang diduga merupakan reservoir karena berada pada dua zona yang memiliki resistivitas kontras yaitu rendah dan tinggi. Reservoir merupakan volume lapisan batu permeabel yang berfungsi menyimpan panas dan tempat sirkulasi fluida yang mengekstrak panas (Kadir, 2011). Sebaran resistivitas sedang juga terdapat di bagian permukaan tepatnya di bawah titik pengukuran MTWP-11 yang menyebar hingga kedalaman $1000 \mathrm{~m}$ di bawah titik pengukuran MTWP-34. Lapisan ini diduga sebagai batuan metamorf karena menurut informasi geologi, batuan yang tersebar di daerah penelitian adalah batuan metamorf.

Lapisan terakhir setelah lapisan dengan sebaran resistivitas rendah dan sedang adalah sebaran resistivitas tinggi. Sebaran resistivitas tinggi berada di kedalaman mulai $2500 \mathrm{~m}$ di bawah titik pengukuran MTWP-21A dan menyebar diagonal di bawah titik pengukuran MTWP-16 dan MTWP 11 hingga kedalaman 
4000 m. Sebaran resistivitas tinggi diduga merupakan lapisan batuan dasar (basement) yang mengalami intrusi sehingga diduga menjadi salah satu sumber panas melihat nilai resistivitas yang tinggi dibandingkan dengan zona lainnya.

Pada lintasan 1, berdasarkan informasi geologi untuk Kawasan Panas Bumi Wapsalit, terdapat struktur patahan yang berada diantara titik ukur MTWP-16 dan MTWP-11. Struktur ini diduga merupakan jalur transportasi fluida yang terperangkap oleh lapisan impermeabel pada batu penudung. Hal ini didukung dengan munculnya mata air panas tidak jauh dari lokasi tersebut. Pada lintasan 1 terdapat pula mata air panas di dekat lokasi titik pengukuran MTWP30, akan tetapi tidak dapat dipastikan letak struktur di sekitar titik MTWP-30. Lapisan batu penudung juga tidak mencakup permukaan namun masih terlihat mendapat sebaran resistivitas rendah dari batu penudung dan terlihat mulai menutup di kedalaman $3000 \mathrm{~m}$ di bawah permukaan tanah. Mata air panas di sekitar titik pengukuran MTWP-30 diduga muncul karena terdapat struktur lain.

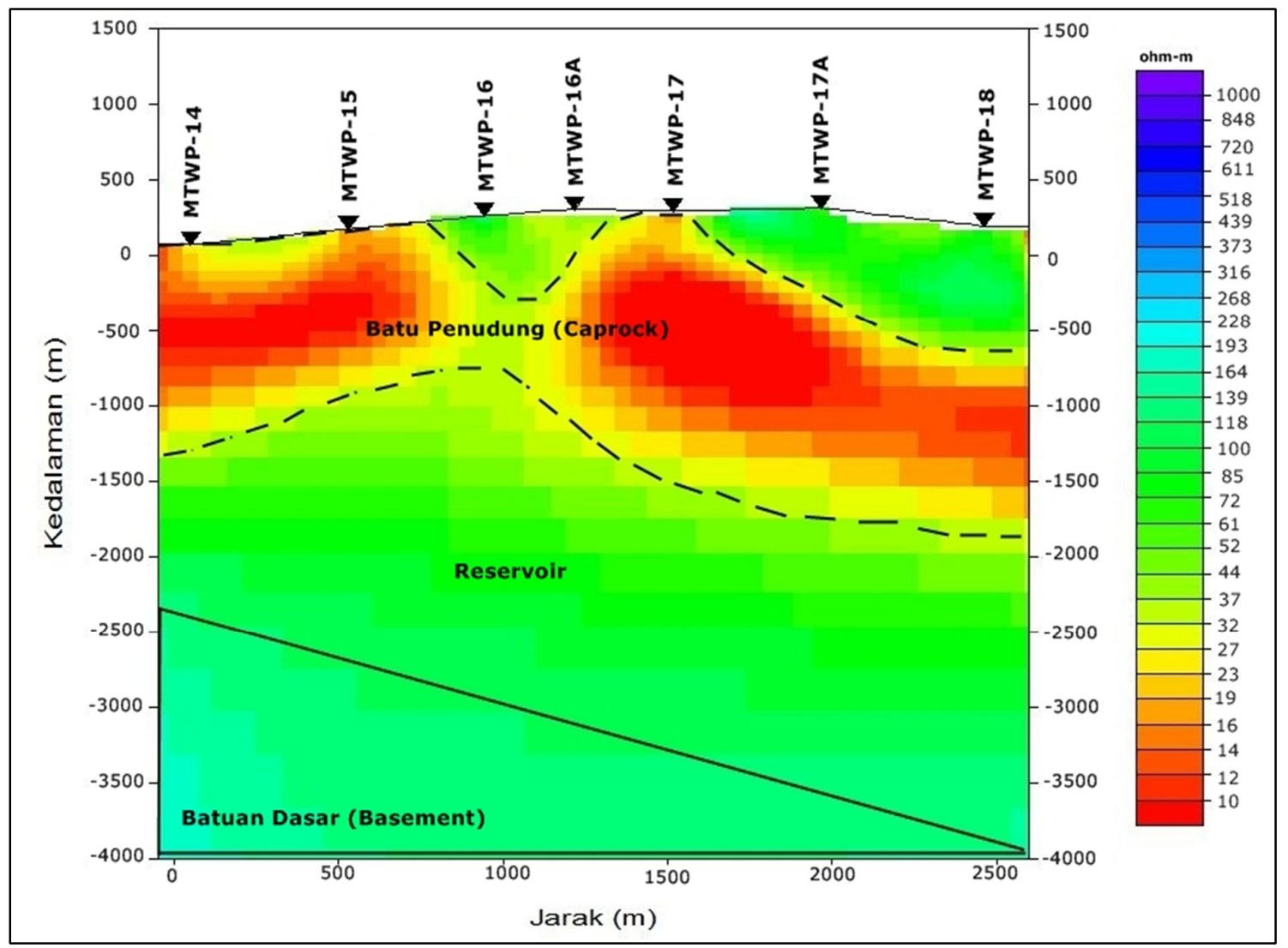

Gambar 4. Model Resistivitas Semu 2D Lintasan 2

\section{Interpretasi model sebaran resistivitas semu 2D lintasan 2}

Lintasan 2 terdiri dari titik pengukuran MTWP-14, MTWP-15, MTWP-16, MTWP 16A, MTWP 17, MTWP-17A dan MTWP-18. Lintasan 2 berarah dari barat daya hingga timur laut. Pada hasil inversi 2D yang terlihat pada gambar 4 , terlihat pula 3 lapisan sebaran resistivitas yang kontras seperti pada lintasan 1 di gambar 3. Terdapat resistivitas rendah ditandai dengan warna merah hingga kuning yang bernilai 1$32 \Omega \mathrm{m}$, resistivitas menengah yang ditandai dengan warna hijau bernilai 32-139 $\Omega$ m, dan resistivitas tinggi yang ditandai dengan warna biru muda sampai biru yang memiliki nilai resistivitas $<139 \Omega \mathrm{m}$.

Pada model sebaran resistivitas lintasan, lapisan resistivitas rendah di dekat permukaan diduga sebagai lapisan batu penudung. Batu penudung berada pada tiap titik pengukuran dan resistivitas cenderung sangat rendah yang ditandai dominasi warna merah ditengah dan diselimuti oleh lapisan yang juga rendah yang ditandai dengan warna oranye hingga kuning. Lapisan batu penudung berada di sepanjang permukaan lintasan hingga pada kedalaman 2000 m. Lapisan dengan resistivitas sedang yang berada pada kedalaman kurang lebih 
1500-3000 m dibawah permukaan diduga sebagai komponen reservoir sedangkan untuk resistivitas cukup tinggi (193-228 $\Omega \mathrm{m})$ yang terlihat berada pada kedalaman lebih dari $2500 \mathrm{~m}$ dibawah permukaan diduga sebagai batuan dasar (basement).

Pada lintasan 2 yang menampilkan kedalaman hingga $4000 \mathrm{~m}$, tidak terlihat lapisan batu batu dasar dengan resistivitas tinggi $(>316 \Omega \mathrm{m}$ ) pada kedalaman $3500 \mathrm{~m}$ seperti pada model 2D pada lintasan 1 yang terlihat hingga berwarna biru tua dengan nilai resistivitas berkisar 611-720 $\Omega \mathrm{m}$. Pada penampang struktur bawah permukaan lintasan 2, diduga bahwa batu penudung, reservoir dan basement masih menyebar di sebelum titik pengukuran MTWP16 hingga titik pengukuran MTWP-18.

Seperti pada lintasan 1, pola resistivitas sedang juga terlihat berada di permukaan lintasan pengukuran. Pada lintasan 2, sebaran tersebut berada di dekat permukaan pada titik pengukuran MTWP-17A hingga MTWP-18. Sebaran ini mencapai kedalaman $500 \mathrm{~m}$ di bawah permukaan. Lapisan ini diduga juga merupakan sebaran batu metamorf. Berdasarkan informasi geologi, pada lintasan 2 terdapat pula struktur patahan seperti pada lintasan 1. Patahan diduga berada diantara titik pengukuran MTWP-15 hingga MTWP-17. Seperti yang telah di tuliskan sebelumnya bahwa patahan merupakan salah satu komponen sistem panas bumi yang berfungsi sebagai jalur transportasi fluida dari reservoir. Banyaknya zona patahan akan menambah jumlah fluida yang muncul ke permukaan. Hal ini diperkuat dengan banyaknya mata air panas yang berada di dekat lintasan 2 .

\section{Kesimpulan}

Setelah melakukan pengolahan data hingga menghasilkan penampang lintasan pengukuran dalam bentuk 2D, dapat disimpulkan bahwa:

1. Pada lintasan 1, sebaran pola resistivitas antara 1-32 $\Omega \mathrm{m}$ yang menyebar diagonal menuju tenggara dari titik MTWP-21A hingga titik MTWP-30 diduga sebagai lapisan batu penudung (caprock). Sebaran pola resistivitas antara 32-139 $\Omega \mathrm{m}$ yang mulai muncul di kedalaman 1200 m hingga mencapai kedalaman $4000 \mathrm{~m}$ di bawah permukaan diduga merupakan reservoir. Sebaran resistivitas dengan nilai lebih dari $139 \Omega \mathrm{m}$ yang berada di kedalaman mulai $2500 \mathrm{~m}$ di bawah permukaan tanah diduga merupakan lapisan batuan dasar (basement).

2. Pada lintasan 2, sebaran pola resistivitas antara 1-32 $\Omega \mathrm{m}$ yang berada di sepanjang permukaan lintasan hingga pada kedalaman 2000 m diduga merupakan lapisan batu penudung (caprock). Sebaran pola resistivitas dengan rentang nilai 32-139 $\Omega \mathrm{m}$ berada pada kedalaman kurang lebih 1500$3000 \mathrm{~m}$ dibawah permukaan diduga sebagai reservoir. Sebaran pola resistivitas dengan rentang nilai 193-228 $\Omega \mathrm{m}$ yang berada pada kedalaman lebih dari $2500 \mathrm{~m}$ dibawah permukaan diduga sebagai batuan dasar (basement).

\section{Daftar Pustaka}

Amriyah, Qonita, 2012, "Pemodelan Data Magnetotellurik Multidimensi untuk Mendelineasi Sistem Geotermal Daerah Tawau Malaysia", Universitas Indonesia, Jakarta, (Skripsi).

Bandono, I.B., 2011, "Potensi Geothermal Indonesia", sumber: www.ibnudwibandono.wordpress.com, diakses pada 18 Mei 2014

Christina, B., 2013, "Energi Panas Bumi, Indonesia Kalah dari Filipina", Liputan Khusus Tempo, Jakarta

Daud, Y., 2010, "Reducing Emission From Geothermal Energy Technology", International Climate Change Workshop, Geothermal Laboratory University of Indonesia, Jakarta

Grandis, H., 2009, "Pengantar Pemodelan Inversi Geofisika”, Institut Teknologi Bandung, Bandung

Grandis, H., 2013, "Metoda Magnetotellurik (MT)", Institut Teknologi Bandung, Bandung

Grant dan Bixley, 2010, "Geothermal Reservoir Engineering", edisi kedua, Academic Press, USA

Kadir, T.V.S., 2011, "Metode Magnetotellurik (MT) untuk Eksplorasi Panasbumi Daerah Lili, Sulawesi Barat, dengan Data Pendukung Metode Gravitasi", Universitas Indonesia, Jakarta, (Skripsi).

Perdana, A.W., 2011, "Metode Controlled Source Audio Frequency Magnetotelluric (CSAMT) untuk Eksplorasi Mineral Emas Daerah "A" dengan Data Pendukung Metode Magnetik dan Geolistrik", Universitas Indonesia, Jakarta, (Skripsi).

Pertamina, 2014, "Tentang Panas Bumi", sumber: $\quad$ www.pge.pertamina.com, diakses pada 28 Maret 2014.

Prihandana dan Hendroko, 2008, "Energi Hijau", Penebar Swadaya, Jakarta

PSDG, 2012, "Laporan Survei Magnetotellurik Daerah Panas Bumi Wapsalit, Kabupaten Buru, Provinsi Maluku" Pusat Sumber Daya Geologi, Bandung. 
Rodie dan Mackie, 2001, "Nonlinear Conjugate Gradients Algorithm for 2D Magnetotelluric Inversion" Jurnal Geophysics Vol.66 No.1

Santoso, D., 2012, "Volkanologi dan Eksplorasi Geotermal", Catatan kuliah Prodi Teknik Geofisika, Penerbit ITB, Bandung.

Saptadji, N.M., 2001, “Teknik Panas Bumi”, Diktat Kuliah Prodi Teknik Perminyakan, Penerbit ITB, Bandung.

Simpson F. dan Bahr K., 2005, "Practical Magnetotellurics", Cambridge University Press, USA.

Tim peta, 2014,https:// petatematikindo. wordpress.com / 2014/ 07/ 19/administasikabupaten-buru-selatan/,diakses tanggal 13 januari 2014. 